\title{
A ENFERMEIRA COMO CURADORA DO PORTADOR DE TRANSTORNO PSÍQUICO: UM RELATO DE EXPERIÊNCIA
}

\author{
THE NURSING PROFESSIONAL AS A CURATOR OF THE MENTAL PATIENT: \\ THE REPORT OF AN EXPERIENCE
}

\section{LA ENFERMERA COMO CURADORA DEL PORTADOR DEL TRASTORNO PSÍQUICO: UN RELATO DE EXPERIENCIA}

Eliani Costa ${ }^{1}$

\begin{abstract}
RESUMO: O presente artigo é um relato de uma experiência vivida com pacientes psiquiátricos do Instituto de Psiquiatria do Estado de Santa Catarina (IPQ) em São José (SC), na qual uma enfermeira inicia um processo de resgate dos benefícios previdenciários de um grupo de pacientes moradores de uma unidade psiquiátrica. Muitos destes benefícios foram retirados dos pacientes sem a anuência dos mesmos e utilizados à sua revelia, na maioria das vezes, em benefício próprio, pela pessoa designada judicialmente curadora.
\end{abstract}

PALAVRAS-CHAVE: enfermagem, psiquiatria forense, curatela, cidadania

ABSTRACTS: The present paper reports the experience of a nurse who starts a process for recuperating the social benefits of a group of intern patients in the Psychiatry Institute of Santa Catarina in São José (SC). Many of the social benefits were taken away from these patients without their approval, and were spent, most of the time, by their legal curators.

KEYWORDS: nursing, forensic psychiatry, curatory, citizenship

RESUMEN: El artículo es el relato de una experiencia vivida con pacientes psiquiátricos del Instituto de Psiquiatría del Estado de Santa Catarina (IPQ) en São José (SC), durante la cual una enfermera empieza un proceso de rescate de los beneficios previdenciarios de un grupo de pacientes que viven en una unidad psiquiátrica. Muchos de esos beneficios se les había quitado a dichos pacientes sin su consentimiento y habían sido usados -en la mayor parte de las veces- en beneficio propio, por la persona nombrada judicialmente como curadora.

PALABRAS CLAVE: enfermería, psiquiatría forense, curatela/curaduria, ciudadanía

Recebido em 12/09/2001

Aprovado em 18/12/2001

\footnotetext{
${ }^{1}$ Enfermeira do Instituto de Psiquiatria. Especialista em Enfermagem do Trabalho e em Metodologia do Ensino para a Profissionalização em Enfermagem. Mestranda do Programa de Pós-graduação em Enfermagem da UFSC.
} 
A Enfermagem Psiquiátrica e Lei estão intimamente envolvidas, embora tenham caráter diferente. Enquanto a enfermagem psiquiátrica presta assistência a individuos, familias e comunidades para que atinjam padrões satisfatórios e produtivos na vida, a lei oferece as regras para conduta comportamental do homem na sociedade, protegendo os seus direitos individuais. Porém, muitas vezes, esta mesma lei, impõe limitações aos direitos, que no caso do portador de transtorno psiquico poderão perdurar para sempre.

O artigo quinto do Código Civil, considera absolutamente incapazes os "loucos de todo o gênero" expressão que, desde 1916, vem sendo discutida e combatida. A apresentação de um comportamento considerado "anormal" por parte de uma pessoa, como, por exemplo, uma simples depressão ou alteração de conduta, é suficiente para que o Estado, chamado a intervir, através de seus agentes, a conduza a um hospital psiquiátrico contra sua vontade. Ali ingressando, ela sofrerá uma série de violências por parte da psiquiatria que nas palavras de Szasz (1976, p.256) podem assim ser expressas: "Com efeito a psiquiatria tem aceitado a função de abrigar os indesejáveis da sociedade. Tal afinal tem sido seu papel há muito. Há mais de cento e cinqüenta anos, o grande psiquiatra francês Philippe Pinel observou: 'os asilos públicos para maniacos têm sido vistos como lugares de confinamento para membros que se tornaram perigosos para a paz da sociedade'".

A primeira lei especifica de proteção ao doente mental, decreto número 1.132, só foi aprovada em 22 de dezembro de 1903. Corrêa (1996, p.8) refere que "as esperanças de que a lei resolvesse a violação dos direitos do doente mental não foram concretizadas. Veio a segunda lei, o Decreto 24.559 , de 3 de julho de 1934 , e tudo continuou como antes. Aliás, diga-se de passagem, essas leis muito pouco foram conhecidas, e se não foram conhecidas, não se podia esperar que ajudassem a superar os preconceitos e tabus que persistem até hoje".

O portador de transtorno psíquico no momento de seu diagnóstico ou de sua internação, recebe o rótulo estigmatizante de "louco", que na maioria das vezes o acompanhará para o resto de sua vida.

Segundo Cooper (1967, p. 35-6) as familias dos pacientes psiquiátricos, empregadores, clinicos gerais, funcionários das instituições psiquiátricas, policia, magistrados, assistentes sociais, psiquiatras e enfermeiros podem ser muito sinceros e dedicados aos pacientes, mas desenvolvem uma violência sutil contra o objeto de seus cuidados. As boas intenções e todas as pompas da respeitabilidade profissional encobrem uma realidade humana cruel. Para Cooper, essa violência, deve ser evidenciada como ação corrosiva da liberdade de uma pessoa sobre a liberdade da outra. Mesmo que não se trate de agressão física, que também pode ocorrer, a ação livre de uma pessoa é capaz de destruir a liberdade de outra, ou, ao menos, paralisá-la pela mitificação.

A supressão dos direitos de cidadão cria uma condição de incapacidade civil e caracteriza uma forma de privação da liberdade.

Considero a doença mental uma das doenças mais incapacitantes que existe. Ela "rouba" do indivíduo além de sua saúde, sua capacidade de decidir, seus direitos políticos, sua privacidade, sua independência, a percepção acurada do mundo, sua capacidade de exprimir sentimentos e emoções e sua dignidade.

Durante muitos anos, presenciei e fui coparticipante das perdas que o portador de transtorno psiquico era submetido no momento de sua internação. Além de despojado de seus pertences, das pessoas e das coisas que o cercavam, com as quais tinha uma relação afetiva, era ursupado também de seus direitos de cidadão. Se este trabalhava, a familia passava a receber seu beneficio através de procuração ou processo de curatela, ${ }^{2}$ que acontecia à sua revelia. Como as internações na grande maioria das vezes, tinham um caráter prolongado quando não definitivo, a familia aos poucos se desligava do problema deixando-o a cargo da instituição, ficando com o dinheiro do cliente para ajudar no provimento familiar.

Desta maneira, a doença mental passava a ser uma forma de sobrevivência para a familia que passava a dispor do benefício, fazendo o uso que the convinha, sem prestar conta à justiça ou ao seu legítimo dono. Por outro lado, quando o cliente não tinha familia ou que o direito de receber seu numerário não lhe era negado judicialmente ou reclamado por qualquer pessoa, o benefício previdenciário era depositado mês a mês na tesouraria do hospital ou numa conta poupança no banco, sem que o mesmo efetivamente fizesse uso do dinheiro que the era de direito.

A cronificação e a institucionalização se processavam, muitas vezes com a intervenção da lei, à revelia do cliente e contra a vontade da instituição. Não raro, as familias com influências politicas, conseguiam que $\mathrm{o}$ individuo permanecesse para sempre na instituição, fato que contribuiu sensivelmente para o acúmulo de pacientes nos hospitais psiquiátricos, levando a super lotação e às condições desumanas de assistência.

${ }^{2}$ Encargo deferido por lei a alguém para reger a pessoa e administrar os bens de outrem, que não pode fazer por si mesmo. A curatela normalmente incide sobre os indivíduos maiores de idade privados de discernimento em face da doença mental, que Ihes tira a capacidade civil. (CORRÊA,1996, p.209). 
Em função da superlotação de clientes no antigo Hospital Colônia Santana (HCS), na década de 80 e estimulados pelo movimento da "Reforma Psiquiátrica" que começava a se instaurar no pais, surgiu um projeto com uma nova proposta assistencial, o Projeto Ana Teresa (COSTA, 1999). Tinha como objetivo central a recuperação das habilidades perdidas e a humanização assistencial através de propostas de recuperação bio-psíquico-social e devolução da cidadania. Buscava preservar a subjetividade do paciente, sua história de vida, suas relações interpessoais instituindo novas modalidades de tratamento, sem chaves e sem muros, mais flexiveis e criativos que atendessem as necessidades individuais de cada um, com suas particularidades, aproximando-os progressivamente da sociedade.

Este trabalho passaria por várias etapas, entre as quais, devolver ao cliente seus documentos ou providenciá-los, oferecer condições de moradia que privilegiasse a privacidade e incentivasse a independência progressiva. Retirou-se a roupagem do "louco", construiu-se um ambiente terapêutico e através do resgate dos aspectos sadios de suas personalidades, avançamos na proposta de humanização da assistência, que se tornou a filosofia do trabalho.

$\mathrm{Na}$ busca da cidadania destes moradores, eu e os demais integrantes da UAT, iniciamos um processo de localizar os registros de nascimento dos clientes e providenciar documentos de identidade e 0 benefício previdenciário para cada um que tivesse direito.

Esses beneficios eram solicitados junto ao Instituto Nacional de Seguridade Social (INSS) e concedidos de acordo com a possibilidade legal de cada beneficiado, seja por que em algum momento de sua vida trabalhou, seja pela Lei Orgânica Assistencial de Saúde (LOAS) ${ }^{3}$, concedida pelo INSS aos portadores de doenças incapacitantes com comprovada necessidade social

Nesta busca, identificamos muitos clientes já aposentados cujas famílias recebiam o benefício, sem nada repassar para seu ente familiar, agora denominado, morador ${ }^{4}$. Ao identificarmos a situação relatada, denunciávamos o fato ao INSS que suspendia o pagamento dos benefícios fazendo com que a família os procurassem para os devidos esclarecimentos.

Desta forma, os familiares forçosamente procuravam o hospital, ocasião em que toda a historia de vida do cliente era revista. Os mais variados fatos e histórias eram repassados neste encontro e na ocasião, resgatávamos o direito do cliente em fazer uso de seu beneficio, seja na forma de acordo ou na forma judicial quando comunicávamos o fato ao Ministério Público.

Inverteu-se imediatamente a relação da familia com estes moradores. Muitas familias que os haviam abandonado, passaram a visitá-los sendo que em algumas situações, o cliente passou a ajudar sua familia, modificando sua condição de "peso morto", para alguém que contribui financeiramente com o sustento familiar. Em outras ocasiões, o cliente voltou a conviver com seus familiares, em suas casas ou em casa para idosos, porém na maioria das vezes, os moradores passaram a receber seu dinheiro, por meio de um cartão magnético ou de recibo bancário. Dirigem-se à agência bancária, digitam sua senha ou assinam um recibo e recebem seus pagamentos sem a intervenção de qualquer pessoa.

Alguns moradores não apresentavam, de fato, condições de administrar este benefício. Estes foram interditados pelo Ministério Público, sendo julgados incapazes de conduzir seus assuntos. Neste caso, havia necessidade de se nomear um tutor ou também chamado de curador.

Solicitei à direção do Hospital que fizesse o encaminhamento do processo junto a Vara da Família do Municipio de São José, com a finalidade de legalizar o uso dos proventos dos clientes em que eu, como enfermeira responsável por esta Unidade, tornava-me curadora do morador.

O HCS, um macro hospital psiquiátrico estatal, não tinha condições de suprir a maioria das necessidades dos clientes internados e faltavam itens básicos para a assistência como medicamentos, roupas, e outros itens para garantir um pouco mais de qualidade de vida aos moradores.

Iniciamos um trabalho de conscientização com os moradores que não eram curatelados, para que usassem seu dinheiro em beneficio próprio, para melhoria das condições de seus quartos, suas roupas, aquisição de medicamentos em falta, compra de ventiladores, eletrodomésticos, passeios, custear seu cigarro, e outras necessidades pessoais.

O benefício dos moradores sob curatela também passou a ser utilizado para o provimento das suas necessidades, e que o estado, como provedor assistencial, não podia cumprir. Todos os gastos efetuados com os moradores decorrentes de seus benefícios, são semestralmente relatados ao Ministério Público através de uma prestação de conta individual, documentada com notas fiscais.

\footnotetext{
${ }^{3}$ Lei $N^{\circ} 8.742$ de 07 de dezembro de 1993. Art. $2^{\circ}$, cap. $V$, que garante um salário mínimo mensal à pessoa portadora de deficiência e ao idoso que comprova não possuir meios de prover a própria manutenção ou tê-la provido pela familia. (FERREIRA, 1999)

${ }^{4}$ Pacientes institucionalizados que moram nas unidades de longa permanência do IPQ (Nota da autora).
} 
Como resultado deste trabalho, 35 dos 50 moradores da Unidade Ana Teresa passaram a receber algum tipo de provimento. Passamos a receber 0 beneficio de sete moradores que foram interditados e de mais outros oito através de procuração de familiares, sendo que os vinte moradores restantes, recebiam sozinhos seus beneficios.

Este foi um trabalho iniciado na Unidade Ana Teresa que foi ampliado para outros pacientes do Centro de Convivência Santana que abriga os demais pacientes remanescentes do antigo Hospital Colônia Santana ${ }^{5}$. Nesta ampliação, o papel de curadora passou a ser desenvolvido por mais uma enfermeira. que sistematizou o processo, sendo que o trabalho assumiu outras características e tornou-se bastante extenso.

Esta atividade constituiu-se em mais uma aproximação do paciente com a realidade social, em que o homem deve prover meios para sua própria subsistência. Acreditamos que com esta prática, avançamos mais um passo na conquista da dignidade e do direito destas pessoas, oportunizando uma liberdade de ter um provimento e escolher a forma de gasta-lo.

Taylor (1992, p. 19) refere que "ter direitos é desfrutar de privilégios assegurados por lei. As pessoas mentalmente enfermas que estão hospitalizadas podem sofrer uma dupla limitação em seus direitos: uma criada pela organização do sistema hospitalar e outra, por sua doença", que também encontra fatores limitantes na lei.

A enfermeira ${ }^{6}$ que trabalha na área de saúde mental deve estar ciente das questões legais (psiquiatria forense ${ }^{7}$ ) que envolve a internação psiquiátrica, conhecer os direitos do cliente, e "advogar" no sentido de defesa em prol da conquista e manutenção dos direitos dos portadores de transtornos psiquicos.
As instituições psiquiátricas enfrentam tensão no sentido de manter as necessidades do pacientes e acreditamos que esta prática, pode contribuir para diminuir as despesas hospitalares, auxiliar a manutenção do espaço físico dos moradores IPQ. A criação das casas lares para os portadores de transtornos mentais abandonados pelos familiares e pela sociedade, além de representa mais um passo na conquista pela cidadania.

\section{REFERÊNCIAS BIBLIOGRÁFICAS}

BRASIL. Lei n. ${ }^{\circ} 10.216$, de 6 de abril de 2001. Dispõe sobre a proteção e os direitos das pessoas portadoras de transtornos mentais e redireciona o modelo assistencial em saúde mental. Brasilia, 2001.

COOPER, D. Psiquiatria e antipsiquiatria. São Paulo: Perspectiva, 1967.

CORREAA, J. M. Um estudo jurídico e político sobre Saúde Mental. Florianópolis, 1996. 238p. Tese (Doutor em Direito) - Curso de Pós-Graduação em Direito da Universidade Federal de Santa Catarina.

COSTA, E.; BORENSTEIN, M. S. O Projeto Ana Teresa: o caminho para a desinstitucionalização do doente mental? Rev. Bras. Enferm., v. 52, n.1, p. 79-90, jan./mar. 1999.

FEREIRA, R. Seguridade Social. Apostila do Curso de Seguridade Social. Instituto Nacional de Seguridade Social- Florianópolis (S.C.), 1999.

SZASZ, T. S. A fabricação da loucura. Rio de Janeiro: Zahar, 1976.

TAYLOR, C. M. Fundamentos de Enfermagem Psiquiátrica de Mereness. Trad. Dayse Batista. Porto Alegre: Artes Médicas, 1992. 465p.

\footnotetext{
${ }^{5} \mathrm{O}$ antigo Hospital Colônia Santana está se reestruturando para atender as prerrogativas da Lei $n^{\circ} 10.216$, de 06 de abril de 2001 (BRASIL, 2001), que dispõe sobre a proteção e os direitos das pessoas portadoras de transtornos mentais e redireciona o modelo assistencial em saúde mental e foi dividido em centro de Convivência Santana e Instituto de Psiquiatria (IPQ). Nota da autora.

${ }^{6}$ A referência à enfermeira (o) será feita sempre no sexo feminino em função da predominância do gênero.

7 A Psiquiatria Forense esta envolvida com determinações de incompetência mental e insanidade, a fim de promover o funcionamento social organizado. (TAYLOR, 1992, p. 25)
} 